\title{
Towards Genuine Virtual Collaboration: Designing the Use of Mobile Remote Presence in Offshore-Outsourced Projects
}

\author{
Dr. Erik Wende \\ University of Zurich \\ wende@ifi.uzh.ch
}

\author{
Prof. Rainer Alt \\ University of Leipzig \\ rainer.alt@uni-leipzig.de
}

\author{
Greg King \\ EWERK GmbH \\ g.king@ewerk.com
}

\begin{abstract}
Informal communication between work team members is critical for collaborative tasks, building relationships and coordinating group activities. Achieving informal communication and collaboration is particularly challenging in in offshore outsourced projects. Supporting informal communication is difficult for most collaboration technologies. One approach is the adoption of mobile remote presence technologies (MRP). Such systems comprise a video conferencing system mounted on a user-controlled, mobile robotic base.

This paper seeks to design the deployment of an MRP system in an offshore-outsourced software development team (located between Germany and India). The design process involved observing the use a MRP system in a distributed team in Germany.

We observed the influence of the mobile remote presence system on types and frequency of team interaction over a 12-month period. It supported a wide range of collaborative interaction, including planned and unplanned meetings and social interactions. After an adjustment period of several weeks, local and remote users worked almost as if they were co-located.

The paper concludes with plans for deploying the mobile remote presence system in an offshore outsourced team, which include an extended adjustment period and daily scheduled meetings to ensure usage and enable a range of interaction types.
\end{abstract}

\section{Introduction}

As many organizations that have implemented a global sourcing strategy have discovered, outsourcing complex projects is not straightforward [1-3]. Establishing informal communication and personal relationships between team members is perhaps the most significant challenge to achieving genuine collaboration in distributed teams [1-4]. A large body of research shows that informal communication is critical to supporting collaborative tasks $[1,5]$.
Remote workers generally have fewer opportunities to engage in informal communication [7]. They also commonly experience much less frequent and less effective communication than do workers in collocated scenarios [5]. In distributed work scenarios such as offshore outsourcing, teams often comprise individuals without a shared national or company culture, or even a common first language [8].

Supporting informal communication is difficult for most collaboration technologies because informal communications are often unscheduled and brief. They require highly interactive and expressive communication channels [6]. One approach to addressing this difficulty is to adopt mobile remote presence (MRP) technologies in the workplace [6]. MRP systems are characterized by a videoconferencing system mounted on a mobile robotic base. The system allows a remote user to move around in the robot's environment and consists of both a physical robot and an interface used to pilot the robot. MRP systems have been found to increase the perceived presence of remote coworkers [9], build social connections among geographically distributed team members [10], and increase the number of impromptu meetings and the amount of informal interaction [6].

The use of MRP systems in office environments is still atypical and has not been subject to a great deal of detailed research. The extant research focuses primarily on the technical aspects and functions of MRP systems [9, 11-14]. We believe there is no extant research that investigates the use of MRP in the context of offshore-outsourced, intercultural teams.

The objective of this research was to design deployment of an MRP system in an offshoreoutsourced software development team. The design process involved investigating the issues associated with using MRP systems in distributed work teams through literature research and practical testing with a locally distributed team. Findings from the investigations were used to propose the design a global deployment. 


\section{The challenge of offshore outsourcing}

For complex offshore projects such as software development, integrating teams effectively and forming relationships between people are essential for effective teamwork [16, 17]. Software development is a complex, collaborative process that relies on unstructured information flow $[1,18]$. If partners do not have a personal, trusting relationship, they will be less inclined to communicate openly, thus impeding collaboration [19]. In offshore outsourcing, a combination of factors makes forming and maintaining teams challenging. It is distinctive in a number of ways, including its geographical distribution, organizational boundaries, and cultural and language differences between teams [20-23].

The development of relationships between partners is associated with the amount and quality of communication [24]. In offshore-outsourced projects, there is commonly less communication and less effective communication and collaboration than in collocated scenarios [5, 8]. Offshore teams often struggle to develop the kind of trust and relationships needed for effective collaboration [26]. It is believed that the lack of physical presence or visual cues associated with computer-mediated communication hinders the development and maintenance of personal relationships. This tends to make remote work teams less collaborative than collocated teams [27].

\section{Forming and maintaining offshore teams}

In response to the challenges noted, a number of strategies for forming and maintaining offshore teams have been proposed. Common approaches include: simply not attempting work that requires intensive collaboration between separated team members [28]; including face-to-face meetings at the beginning of a team relationship and selected stages in the project cycle[29-31], and; adopting collaboration technologies to support remote work $[32,33]$.

To understand the context of our research better, we describe some of the key literature related to the concepts of forming and maintaining teams.

Tuckman (1965) identified four distinct stages of team development: forming, storming, norming, and performing. During the forming stage, team members share information about themselves and the task. Ideally, team members also establish trust, clarify group goals, and develop shared expectations in this stage. The storming stage includes efforts to resolve differences of opinion and other conflicts that might emerge. Groups that are able to resolve conflicts move to the norming stage. In this stage, teams agree on ways of working together, which strengthens relationships and increases trust, mission clarity, and coordination. Finally, teams reach the performing stage, in which team members work toward project completion while actively helping and encouraging each other [34, 35]. Tuckman's model has been subject to criticism, including questions over applicability to different types of teams and weak definition of the "storming" stage [38]. However, it is the most widely recognized team development model in the organizational literature [39] and remains the baseline of terms and ideas in both academia and practice [38].

Furst (2004) explored which factors contribute to team performance at each stage and identified the special challenges that confront virtual project teams as they develop [34]. Furst found that working virtually delayed team progress through the forming stage by diminishing opportunities to communicate [34]. Findings showed the critical role of proactive management in the early stages of team development. Managers help teams define their mission, set guidelines and accountabilities, and build confidence, facilitating team formation and reducing the length of the storming stage [34].

Furst contends that for virtual teams, face-to-face team-building sessions are highly recommended early in the team development process to reduce the impact of an unsuccessful storming stage on team development. Meeting face to face provides the richest possible communication context and often proves critical for overcoming problems encountered early in a virtual team's development [34].

Many researchers concur that face-to-face interaction at the team-building stage may be essential to establishing interpersonal ties as a basis for effective collaboration [28, 31]. Others argue that face-to-face meetings, though very much needed, still pose challenges to globally distributed teams [31]. Face-toface meetings are typically too infrequent to support interpersonal relationships [31]. Oshri (2008) found that even with reasonably regular face-to-face meetings, maintaining relationships was difficult because bonds faded between meetings. This often led to failed collaboration between remote counterparts [31].

Research by Wende (2013) investigated strategies for team development in offshore teams for which face-to-face contact was not possible at any stage. This found that adopting videoconferencing as a substitute for face-to-face interaction could be problematic for new, culturally diverse teams [36]. The cognitive workload of a videoconference meeting is higher than that of a face-to-face meeting [37]. When compounded by unfamiliar accents and differing communication norms or expectations, the risk of information overload 
and/or communication breakdown was significant in the first few meetings [36]. As other researchers have identified, failed opening encounters between team members often result in ongoing problems for team development and achieving collaboration [29, 30].

Wende (2013) nevertheless recognized the powerful reasons for synchronous, if not face-to-face, communication in collaborative work [28]. He devised an approach in which initial contact between team members was via a rich, asynchronous medium (recorded video). This enabled counterparts to gain familiarity with each other (and each other's accents) in a low-pressure setting. When a synchronous medium (videoconferencing) was used later in the project, this familiarity contributed to improved interaction [36]. Wende proposed that this gradual team integration might be the best approach for new, culturally diverse teams that are at risk of miscommunication or communication breakdown [28].

\section{MRP in business}

Given the increasing importance and ongoing challenges of separated work teams, there has been growing interest in all types of collaboration technologies, including MRP systems. Several MRP systems are available on the market. Those noted in the literature include QB, Texai, VGo, and Double (which was used in this research). With respect to the terminology used to describe MRP users, a pilot user is a person who remotely connects to a robot via a computer interface. The pilot of the MRP system can move the robot around in its environment and interact with other persons. A local user is one who is situated in the same physical location as the robot [9].

MRP systems have been utilized in office contexts since approximately 2002 [9]. There has been increased research interest in MRP in the last five years (particularly that described in [6,9]. A large segment of the research has been performed at companies within the United States that had largely culturally homogeneous teams [6]. The motivations cited in the literature for adopting MRP systems include enabling remote coworkers to visit local coworkers and participate in formal and informal meetings, reducing travel for employees and travel costs for companies, and providing immediate access to another site where employees are needed [6, 9].

Although research identified a number of challenges associated with adopting MRP systems, the findings have been overwhelmingly positive. Extended field research has found that pilots and local users worked together almost as if the pilots were there physically. Users perceived the MRP system to be useful and effective. It was used for a range of activities, including impromptu and planned meetings and collaborative problem solving $[6,9]$.

MRP systems were found to support informal and social communications more than other media. They were also found to have clear advantages over telephone and static videoconferencing technology because they supported meetings away from usual meeting places. As such, the MRP systems enabled meetings between remote colleagues that otherwise would not have happened [6]. Furthermore, the characteristics of user control and independent movement resulted in higher perceptions of social presence than were seen with static videoconferencing. In one piece of research, Lee (2011) found that the MRP system was especially beneficial for previously unknown counterparts. Respondents who did not know each other before the introduction of the MRP reported greater benefits than those who were already familiar with one another [6].

Challenges identified with MRP systems were mainly related to sound perception and sound disturbance (as many office environments are open workplaces). In particular, local users frequently perceived pilots as being too loud [6].

\section{Research approach}

To complement the literature research presented above, we observed a small-scale case study to gain a deeper practical understanding of MRP use in an office environment. This comprised the introduction of an MRP system in a partially distributed software development team at a German IT services company. The opportunity for this investigation came about when a project manager from the IT company relocated to a different German city and worked remotely. The project manager continued to manage teams using the MRP system.

We observed team interactions and performed interviews with participants before and after deployment of the MRP system to gain insight into the types and frequency of interactions and the users' perceptions of the MRP system (before and during implementation). The MRP system used in the research was the Double from Double Robotics. This is a commercially available, Segway-like, lightweight MRP robot. The robot uses an iPad as a head and is remotely controlled through an iPad app that the pilot uses to connect to the robot [9].

\section{Observation of the team before deploying the Double}


The team was observed for a three-week period before introducing the Double, to determine the type and frequency of interactions taking place between team members. The observation period occurred immediately before the project manager relocated to a different city.

Through observation and interviews, we recorded the number of interactions (meetings, conversations, etc.), the nature of interactions (e.g., planned or unplanned and work focused or social), and the time and duration of interactions.

The observed team comprised a project manager and 7 software developers of differing levels of expertise. Two members were part-time students. The team members all knew each other relatively well. Most had worked together for a period of at least two months. The team was involved in two associated software development projects. The projects were for the same customer and were to be simultaneously deployed. One of the projects was already in development when our observation started. The other project started within the period of observation. The projects were moderately complex and required collaboration between team members. The team was part of the company's software development department, which comprised approximately 25 software developers and project managers.

Observations revealed that team members engaged in four broad types of face-to-face interactions. We refer to these as planned meetings, unplanned meetings, social encounters, and planned social events. In addition, the team communicated regularly via textbased media. This was mainly instant messaging (for sharing notes, links, code snippets, etc.) and short messages within a shared online project-tracking platform.

Planned meetings mainly comprised biweekly stand-up meetings, which took place every Tuesday and Thursday morning and involved the whole software development department. In these meetings, every member of the department would state what he or she was currently working on, what they had done in the last few days, and what they planned to do in the next few days. The main purpose of the meetings was to share information and to ensure that the whole department was aware of the project's progress. A secondary purpose of the meeting was to keep the whole department aware of the expertise and experience of other team members. This was intended to enable effective support and collaboration within the teams, as people would know whom they had to speak to for help.

The stand-up meetings typically took 10-15 minutes and happened in the main room of the software development department. Each team member would speak for 30-60 seconds. In addition, a meeting coordinator (a designated project manager) would give some additional information, such as company updates. During the meetings, all dialogue was project or taskfocused.

The other type of planned meeting observed was an internal project initiation meeting, or kick-off meeting. This was arranged by the project manager to introduce a new project to the developers. It was a sit-down, face-to-face meeting that took place in a dedicated meeting space outside the main room of the department. It involved the project manager describing the background, requirements, responsibilities, and actions associated with the new project.

The meeting dialogue was all project or taskfocused. Nevertheless, the dialogue between the project manager and the developers was relaxed, open, and collaborative. There was a significant amount of back-and-forth interaction between team members. The project manager spoke for approximately $50 \%$ of the meeting. The developers interrupted the project manager to ask for clarification or to make comments as needed.

Unplanned meetings were impromptu gatherings between the project manager and team members to discuss project/task specifics or to gather progress updates. Such meetings occurred typically two to three times per day and were short (5-15 minutes). Most occurred at desks. In an interview, the project manager explained that the number of unplanned meetings varied considerably according to the project phase. Early in the project cycle, there may be five or more unplanned meetings in a day, whereas later in a project, there may be only one or two per week. These meetings involved the project manager and 1 or 2 developers. Meetings were usually (in $75 \%$ of instances) instigated by a developer to clarify or request guidance on a specific task. The other $25 \%$ of instances were instigated by the project manager to check a developer's progress or provide further details on a particular task. In interviews, both the project manager and the developers stated that this type of meeting is highly important to effective project work. The project manager said:

"It is a key part because only in personal meetings can you discuss complex problems. Complex problems which are written down in the ticket, but not everything is written down or something is unclear. So it can be quicker and easier when you go to the desk and talk about it instead. That's better than taking a long time to write it down in a ticket or in Skype. The other guy might not be looking at Skype at that time..."

Social encounters between team members occurred in four situations: when arriving/leaving the office at the beginning/end of the workday, before/after planned 
meetings, during random encounters in hallways or kitchen, and at a worker's desk. Such encounters tended to be very short (1-4 minutes), and conversation was mainly on topics other than work (recent experiences, current affairs, shared interests, etc.). In general, team members were involved in between 6 and 12 social encounters per day. Most of these involved at-desk dialogue or random encounters in the hallways or kitchen.

Planned social events include gatherings in the office for celebrations such as birthdays. These occurred approximately once every 3-5 weeks and lasted approximately 15-30 minutes and happened within the office. In addition, colleagues from the software development department and other departments often shared lunch breaks.

Before the project manager relocated to a different city and began using the Double, he and other team members were interviewed to gain insight into their perceptions of the upcoming change in working arrangements.

All team members thought that the project manager's relocation would result in changes to working practices. The project manager predicted that there would be a reduction in short, unplanned meetings:

"I think we will have to summarize our questions and only talk to each other when we have a block of questions."

There was a mixed view within the team about whether this was a positive or negative change. The developers voiced concern that it would be more difficult to discuss points or to get help when needed. Conversely, the project manager perceived this as an improvement:

"I think that may be also an advantage, because then I'm not interrupted in my work for small questions or just a couple of questions. Or the question is put into Redmine [the shared project platform] and when I have time to organize Redmine tickets then I see the question and that's the right time for me and not an interruption when I do something completely different."

When we discussed the plan to introduce the Double to support team coordination, all team members agreed that there would be an initial novelty period. One developer commented:

"I think if someone is on an iPad on wheels and rolls around the office and wants to speak to me, the first that I would want to do is laugh. It's quite a funny situation, but only because it is not a normal thing. And when it's 3 months later and it's normal to have someone driving around the office, then it's not funny anymore."
All team members were interested in the idea of using the Double, but there were mixed views on the system's utility. Two developers were skeptical that it would have any advantages over desktop videoconferencing. One stated:

"I'm not sure what the point is. It's just Skype isn't it? We already have that."

The project manager thought that the Double would be useful for planned meetings, such as stand-up meetings (which happen away from desks). However, he did not think there would be other significant uses, such as unplanned meetings or social encounters. When asked how he thought he might use the Double, he said:

"I think I will use it only for meetings, when I have something that I want to discuss. But I don't think I will just roll though the office. I don't even do that when I'm actually here. It's just when I go to the kitchen or the toilet, then I look through the office. That's something I don't want to do with the Double."

\section{Deployment - Usage and findings}

As noted, following the three-week observation of the collocated team, the project manager relocated to a different city in Germany, where he worked from a home office. The project manager's new location was a three-hour journey from the company's headquarters. It was initially planned that he would work at the headquarters one day per week and from his home office on the other days.

The Double was introduced to support interaction and coordination between the project manager and other team members. The Double robot itself was located at the company headquarters, within the software development department. According to the terminology from the literature, the project manager was the pilot, and the developers were the local users.

We observed the introduction and use of the Double for a 15-month period. Over this time, the team experienced a range of benefits from and challenges with the system. Influenced by these issues, usage of the Double changed and evolved over time, as we describe here.

\subsection{The first month of usage}

As anticipated, there was a novelty period following the introduction of the Double. For everyone in the software development department, the Double was an interesting, unusual, and often funny tool. For the project manager, the first impression of the Double was that it was fun to use. He reported that it was a strange and fun experience to remotely drive around 
the office. Several local users reported a sense of surprise that the Double felt so different from regular desktop videoconferencing. As has been reported in other research, the sense of social and physical presence was significantly increased. One developer stated:

"I'm actually really surprised what a difference it makes. That he can move around on his own makes it like he's really here."

The team initially used the Double for three types of meetings, with mixed success. The project manager attended the regular departmental stand-up meetings. This was relatively successful from the beginning, and he was able to participate in the meetings. He gave his update as usual, and it was understood well by everyone in the meeting. The project manager could also understand most updates from his colleagues without difficulty.

The project manager attempted to use the Double for short, unplanned meetings with team members at their desks, which had mixed success initially. Conversation was possible, but it was observed to be quite disruptive to other people in the office because of the volume. As has been found with static videoconferencing in other office environments, users tended to speak louder than they would in a face-toface conversation. Furthermore, some developers reported that they felt self-conscious speaking to the project manager at their desks via the Double because it was an unusual experience and they felt that the whole office was watching them. There was also an issue about who instigated the unplanned meetings. As noted, while the team was collocated, developers instigated most unplanned meetings to ask questions. With the Double in use, only the project manager could instigate such meetings.

These perceived downsides quickly started to influence usage of the Double. It continued to be used successfully for regular stand-up meetings. However, after the first few days, there was a reluctance to use it for unplanned meetings, and this type of meeting was rarely undertaken. Instead, instant messaging became the most common mode of communication between developers and the project manager. Coupled with this, the days when the project manager was in the office became increasingly important. The project manager and developers would save up more difficult or technical questions for the days he was there.

In the first month, there were also some technical problems with the Double, and a lost connection was experienced approximately half of the times it was used. This added to the team's early reluctance to use it.

A month after introducing the Double, a short review was undertaken (which we participated in).
This identified the mixed success described above and highlighted some other issues. Of particular interest to us was the limited range of encounters supported by the Double. Of the four interaction types identified in the analysis of the team (planned meetings, unplanned meetings, social encounters, and planned social events), only planned meetings were considered a real success. While the Double was useful for transferring updates and basic information, it was not used for real collaborative work, like problem solving. This occurred only on the days that the project manager was in the office. The shortage of social encounters supported by the Double was of particular interest. In the first month, the project manager participated in only 5 social encounters with the Double, all of which occurred before stand-up meetings. It became the norm for all of the project manager's social encounters to happen when he was in the office.

\subsection{Months 2-3}

Based on the findings from the first month of usage, the team made some changes with the hope of enhancing the utility of the Double. First, updating the software and boosting the Wi-Fi strength resolved the technical problems. Second, the arrangement of planned meetings was altered to increase the use of the Double. The team instigated a daily stand-up meeting, which took place outside the software development department in a nearby meeting space. Third, the location of the Double's docking station was moved from the department to a nearby kitchen area that was used by approximately half of the company.

Observations from month 2 onwards found that the novelty period was certainly over. Despite relatively low levels of usage in the first month, the company was already used to the Double's presence, and it was considered normal within the software development department.

Changing the arrangement of planned meetings changed the Double's usage and altered the working practices that had begun to emerge in the first month. By initiating team stand-up meetings outside the software development department, all developers become comfortable using the Double. Their selfconsciousness and reluctance appeared to disappear.

As hoped, locating the Double's docking station in the shared kitchen resulted in several chance encounters with other members of the company, which did not happen in the first month. However, the project manager indicated that relocating the Double had a small productivity cost due to the time needed to drive through the office to meeting locations.

Overall, the number and range of interactions via the Double increased significantly after the first month. 
However, the number of unplanned meetings remained very low. This was largely compensated for by the significant increase in regularly planned meetings. Developers tended to save up more difficult or technical questions for the daily stand-up meetings. This meant improved productivity compared with the first month, when they tended to save up such questions for several days. Furthermore, the nature of the stand-up meetings changed considerably from simple updates to collaborative interaction. The majority of meetings had a collaborative element, in which two or more team members engaged in a back and forth interaction.

The number of social encounters was significantly higher than in the first month. This was partly due to relocating the Double's docking station. Despite the project manager's belief before deployment that he would not use the Double for social interaction, this became a regular occurrence. On most days, the project manager would have 2 or 3 social encounters with colleagues outside of his immediate team. These occurred either in the kitchen or in the hallway en route to a meeting area. There was also a significant increase in the amount of social interaction between the project manager and the developers. This occurred before and after (and sometimes during) the daily team stand-up meetings. We noticed on several occasions that social dialogue was triggered by what people could see onscreen. For example, the project manager sometimes piloted the Double from different locations in his house. Local users were able to see items and pictures in his house, which they commented on, starting short conversations.

Several planned social events occurred during months 2-3. The project manager attended one of these (a birthday gathering) with the Double, but it was only a limited success. It was difficult to engage in conversation with people in a large-group setting. This was partly because of audio quality. It was difficult for the project manager to hear what people were saying to him because the Double's microphone was picking up other nearby conversations. Furthermore, he said it felt strange attending a party from his desk. He decided not to participate in that kind of event again.

\subsection{Months 4 to 12}

Usage of the Double became increasing normalized over the course of the next few months. The team continued to use the Double largely as described above. Nevertheless, there were several further developments and observations that are worth noting.

The daily team stand-up meetings continued to be the main form of dialogue between the project manager and developers. In addition, there started to be a few more unplanned collaborative at-desk meetings (typically 3 or 4 per week). Often, these would happen directly after a stand-up meeting, when a point for further discussion was identified. A developer instigated some at-desk meetings, by sending a request to the project manager via email or instant message. It appeared that the developers' reluctance to use the Double at their desks was now completely gone. Furthermore, the disruption to the rest of the office from the volume of the Double, which had been experienced in the first month, appeared to be much reduced. The reason for this reduction was not clear. It could be because the software development department had expanded in the intervening period, meaning that there was more activity and ambient noise in the room. It could also be that people had simply become more familiar with the Double.

In interviews, all team members perceived that the Double had become a useful and effective tool. The project manager stated on several occasions that it offered little or no disadvantage compared with working in the office. This influenced his working practices. He would often visit the office only once every two or three weeks, rather than every week. Increasingly, the project manager's office days were influenced more by external client meetings and planned social events than by a desire to spend time in the office.

Moreover, the days when the project manager was in the office and the days when he was not became increasingly seamless. For the project manager, there was almost no difference in the number and type of interactions whether he was in the office or not.

Table 1: Project manager's interaction types and frequency.

\begin{tabular}{|l|c|c|c|c|}
\hline \multirow{2}{*}{$\begin{array}{l}\text { Interaction } \\
\text { type }\end{array}$} & \multicolumn{4}{|c|}{ Average number of weekly occurrences } \\
\cline { 2 - 5 } & $\begin{array}{c}\text { Before } \\
\text { deployment }\end{array}$ & $\begin{array}{c}\text { Month } \\
1\end{array}$ & $\begin{array}{c}\text { Months } \\
2-3\end{array}$ & $\begin{array}{c}\text { Months } \\
4-12\end{array}$ \\
\hline $\begin{array}{l}\text { Planned } \\
\text { meetings }\end{array}$ & $2-3$ & 2 & $5-6$ & $5-6$ \\
\hline $\begin{array}{l}\text { Unplanned } \\
\text { meetings }\end{array}$ & $10-15$ & $1-2$ & $0-1$ & $3-4$ \\
\hline $\begin{array}{l}\text { Social } \\
\text { encounters }\end{array}$ & $30-60$ & $1-2$ & $12-20$ & $15-25$ \\
\hline $\begin{array}{l}\text { Planned } \\
\text { social } \\
\text { events }\end{array}$ & $0-1$ & 0 & $0-1$ & 0 \\
\hline
\end{tabular}

During months 4-12, several projects concluded while new ones started, and there were some changes to the team. This included a new employee joining the team. The project manager and the new employee met for the first time via the Double. In addition, the 
Double was used for project kick-off meetings. It was observed to support open interaction similar to those the project manager experienced in collocated kick-off meetings.

\section{Design of MRP deployment in an offshore outsourced team}

As noted, the focus of this research is to design the deployment of an MRP system with an offshore outsourced team. The Double will be introduced to a new team, comprising a project manager and senior developer in Germany and a group of developers in India. The plan is to have a Double at both locations.

From our literature and practical investigation we propose several strategies for implementing an MRP system effectively.

- Time needs to be allotted for local users to gain familiarity with the system to overcome the novelty period and overcome any initial reluctance or self-consciousness.

- Instituting regularly planned meetings is an effective way of enabling social interactions. Many social interactions occurred before, after, or en route to planned meetings.

- Locating the docking station in a gathering place away from desks and main meeting areas increases the likelihood of unplanned social encounters. Nevertheless, it must be accepted that this comes at a small time-efficiency cost.

- Social conversations can be triggered by what is visible in the background. Users can see and comment on surroundings as a basis for conversation.

Clearly, the international deployment has significant differences to the local deployment. The differences are: the team members are unknown to each other at the start of the relationship; the team comprises employees of separate companies in a client-service provider relationship; team members are culturally diverse (in terms of both national and organizational culture) and do not have a shared first language; team members are a significant distance apart, are in different time zones, and are not able to meet face to face at any stage. These differences must influence the deployment design.

Here we set out our proposed deployment design. We group the deployment design according to Tuckman's (1965) four stages of work team development.

\subsection{Forming}

As described, the opening encounters between team members can be crucial to team development and project outcomes $[29,30,36]$. As such, the teamforming stage can be considered the most important.

Given the culturally diverse nature of the offshore team, we propose to follow the slow team integration approach proposed by Wende (2013). Team members will be introduced initially via recorded videos produced by both sides of the team. This will enable counterparts to gain familiarity with each other (and each other's accents) in a low-stress setting.

As Furst (2004) noted, the active involvement of a project manager is essential in the early stages of team development to define the mission and facilitate team formation [34]. Beginning interaction via recorded video enables the project manager to carefully craft appropriate opening communications that can set the tone for the relationship.

We plan for the first synchronous interaction between team members to be via the Double, with the purpose of familiarizing team members with the Double itself, rather than a focus on the project. As we found, using the Double is quite fun, and we hope that this will be a lighthearted social interaction that will aid relationship development. This is also influenced by findings from Ellis (2008) emphasizing fun and engagement as an effective strategy in early team building exercises [40].

\subsection{Storming}

As noted earlier, poor definition and questionable applicability of the storming stage was one of the principle criticisms of Tuckman's model [38]. Influenced by this, our intention is that a carefully planned and implemented forming stage will avoid the need for any kind of storming. Indeed, owing to the challenges with offshore-outsourced teams, it is doubtful that effective storming would be possible. The open dialogue required for resolving differences of opinion and other conflicts is very difficult to achieve in the early stages of offshore-outsourced projects, particularly with culturally diverse teams.

\subsection{Norming}

The norming stage is intended to comprise the further development of team relationships and the implementation and consolidation of standard communication practices. Time will be allotted for overcoming the expected novelty period of using the Double. In line with the strategy identified above, regular, planned meetings will be instituted between development team and project manager. It is intended that this will maximize usage of the Double and enable 
regular social interactions. Given the cultural and organizational separation between team members, we foresee that the project manager will be required take a proactive role in instigating social interaction before and after meetings.

Furthermore, the Double docking station will be located in the shared kitchen to increase the likelihood of unplanned social encounters when the Double is in transit.

\subsection{Performing}

Performing is the ideal outcome of using the Double. We will observe whether effective, open, and regular dialogue between team members is achieved as a basis for strong relationships and genuine collaboration. We anticipate a key role for the project manager in ongoing efforts to maintain a supportive work context for the team [34]. This might include proactive strategies to sustain and further develop personal relationships, such as introducing conversation topics in meetings and changing meeting locations to encourage dialogue.

\section{Conclusion and Limitations}

A clear limitation of the research is the noted contextual differences between the test scenario and the proposed international deployment. Further research is required to fully investigate the efficacy of the proposed deployment design for offshore outsourced projects. Furthermore, the scale of the practical study limits the research. As such, certainty

\section{References}

[1] Carmel, E., Global Software Teams: Collaboration across Borders and Time Zones, Prentice Hall, Saddle River, NJ, 1999.

[2] Casey, V., and Richardson, I., "The Impact of Fear on the Operation of Virtual Teams", ICGSE, 2008, pp. 163-172.

[3] Prikladnicki, R., Audy, J.L.N., and Evaristo, J.R., "Global Software Development in Practice Lessons Learned", Software Process: Improvement and Practice, 2003,

[4] Hinds, P., and Mortensen, M., "Understanding Conflict in Geographically Distributed Teams: The Moderating Effects of Shared Identity, Shared Context, and Spontaneous Communication", Organization Science, 16(3), 2005, pp. 290307.

[5] Herbsleb, J.D., "Global Software Engineering: The Future of Socio-Technical Coordination", Future of Software Engineering, 2007, pp. 188-198.

[6] Lee, M.K., And Leila Takayama, "Now, I Have a Body: Uses and Social Norms for Mobile Remote Presence in the about causes of observed phenomena is not possible. Additional investigation is required to determine the generalizability of findings.

These limitations notwithstanding, the research makes a number of contributions. It is one of the first pieces of practical research into MRP usage in office teams outside the USA. Several findings corroborate and extend current research.

Most significantly, we identified that the level of social interaction supported by an MRP is heavily influenced by the usage arrangements. This is particularly in terms of meeting location and scheduling. The practical measures proposed in this research offer strategies for implementing MRP to overcome the issue of conversations in virtual teams being overly task-focused, to the detriment of relational links between team members [40].

As Lee et al. (2011) found, the MRP system enabled a broad range of meeting types and supported encounters that otherwise would not have happened [6]. The effect of physical embodiment increased feelings of social presence-contrary to the prior skepticism of users $[6,9]$. After an initial adjustment period, users were able to interact almost as if they were located together, with no significant downsides. The MRP system was found to support teamwork and collaboration similar to that of a collocated team. Further research is planned into the potential of MRP systems to support genuine collaboration in offshore settings, which is notoriously difficult [1-4]. The findings and deployment design presented in this paper provide the basis for further research.

Workplace", Proceedings of the SIGCHI Conference on Human Factors in Computing Systems, 2011, pp. 33-42.

[7] Chua, A., and Pan, S., "Knowledge Transfer and Organizational Learning in Is Offshore Sourcing", Omega, 36(2), 2008, pp. 267-281.

[8] Herbsleb, J.D., and Mockus, A., "An Empirical Study of Speed and Communication in Globally Distributed Software Development", IEEE Transactions on Software Engineering, 29(6), 2003, pp. 481-494.

[9] Kristoffersson, A., Silvia Coradeschi, and Amy Loutfi, "A Review of Mobile Robotic Telepresence", Advances in Human-Computer Interaction, 3(2013,

[10] Nardi, B.A., "Beyond Bandwidth: Dimensions in Connection in Interpersonal Communication.", CSCW, 14(2005, pp. 91-130.

[11] Desai, M., Et Al., "Essential Features of Telepresence Robots", Technologies for Practical Robot Applications (TePRA), IEEE, 2011,

[12] Edwards, J., "Telepresence Virtual Reality in the Real World", IEEE Signal Processing Magazine, 2011, 
[13] Kiselev, A., Annica Kristoffersson, and Amy Loutfi., "The Effect of Field of View on Social Interaction in Mobile Robotic Telepresence Systems", in (Editor, 'ed.'^'eds.'): Book The Effect of Field of View on Social Interaction in Mobile Robotic Telepresence Systems, ACM, 2014

[14] Tsui, K.M., Et Al., "Telepresence Robots Roam the Halls of My Office Building", HRI 2011 Workshop, 58(2011,

[15] Feintzeig, R., "At Mit, Mastering the Science of Working from Home", Wall Street Journal, 2015,

[16] Lanubile, F., Daniela Damian, and Heather L. Oppenheimer, "Global Software Development: Technical, Organizational, and Social Challenges", ACM SIGSOFT Software Engineering Notes, 28(3), 2003,

[17] Oshri, I., Kotlarsky, J., and Willcocks, L.P., "Global Software Development: Exploring Socialization and Face-toFace Meetings in Distributed Strategic Projects", Journal of Strategic Information Systems, 16(1), 2007, pp. 25-49.

[18] Herbsleb, J.D., and Moitra, D., "Global Software Development", Software, 18(2), 2001, pp. 16-20.

[19] Betz, S., Oberweis, A., and Stephan, R., "Knowledge Transfer in It Offshore Outsourcing Projects: An Analysis of the Current State and Best Practices", International Conference on Global Software Engineering, 2010

[20] Cummings, J., and Teng, B.-S., "Transferring R\&Amp;D Knowledge: The Key Factors Affecting Knowledge Transfer Success", J. Eng. Technol. Manage, 20(2003, pp. 29.

[21] Espinosa, J.A., Delone, W.H., and Lee, G., "Global Boundaries, Task Processes and Is Project Success: A Field Study", Information Technology \&amp; People, 2006,

[22] Fong Boh, W., Slaughter, S.A., and Espinosa, J.A., "Learning from Experience in Software Development: A Multilevel Analysis", Management Science, 53(8), 2007, pp. 1315-1331.

[23] Levina, N., and Vaast, E., "Turning Collaboration into Transaction: A Case of Intranet Use in Boundary-Spanning ...", HICSS, 2005,

[24] Kern, T., \& Willcocks, L., "Exploring Information Technology Outsourcing Relationships: Theory and Practice.", The Journal of Strategic Information Systems, 9(4), 2000, pp. 321-350.

[25] Easton, G., Industrial Networks: A Review. In: Axelson, B., Easton, G. (Eds.). Industrial Networks: A New View of Reality., Routledge, London, 1992.

[26] Carmel, E., and Abbott, P., "Configurations of Global Software Development: Offshore Versus Nearshore", ICGSE, 2006, pp. 3-7.

[27] Olaniran, B.A., Natasha Rodriguez, and Indi M. Williams, "Social Information Processing Theory (Sipt): A Cultural Perspective for International Online Communication Environment.", Computer-mediated communication across cultures: International interactions in online environments, 2011, pp. 45-65.

[28] Carmel, E., and Agarwal, R., "Tactical Approaches for Alleviating Distance in Global Software Development", Software, 18(2), 2001, pp. 22-29.
[29] Kennedy, D.M., Vozdolska, R.R., and Mccomb, S.A., "Team Decision Making in Computer-Supported Cooperative Work: How Initial Computer-Mediated or Face-to-Face Meetings Set the Stage for Later Outcomes*", Decision Sciences, 41(4), 2010, pp. 933-954.

[30] Cramton, C.D., "The Mutual Knowledge Problem and Its Consequences for Dispersed Collaboration", Organization Science, 12(3), 2001, pp. 346-371.

[31] Oshri, I., Kotlarsky, J., and Willcocks, L.P., "Missing Links: Building Critical Social Ties for Global Collaborative Teamwork", Communications of the ACM, 51(4), 2008,

[32] Milewski, A.E., Tremaine, M., Egan, R., Zhang, S., Kobler, F., and O\&Apos;Sullivan, P., "Guidelines for Effective Bridging in Global Software Engineering", ICGSE, 2008, pp. 23-32.

[33] Bloch, M., Weinberg, A., and Boskovic, D., "How Innovators Are Changing It Offshoring", McKinsey on Business Technology, 17(2009, pp. 1-7.

[34] Furst, S.A., Et A1., "Managing the Life Cycle of Virtual Teams", The Academy of Management Executive, 18(2), 2004, pp. 6-20.

[35] Tuckman, B.W., "Developmental Sequence in Small Groups", Psychological Bulletin, 63(6), 1965, pp. 384.

[36] Wende, E., King, G., , "Development and Evaluation of Kaiwa: A Method for Knowledge Transfer in the Transition Phase of Offshore Outsourced Projects", Advances in Global Sourcing. Models, Governance, and Relationships, 2013, pp. 180-191.

[37] O'connaill, B.W., S. And Wilbur S., "Conversation over Video-Conferences: An Evaluation of the Spoken Aspects of Video-Mediated Communication", Human-computer interaction, 8 1993, pp. 389-428.

[38] Bonebright, D, "40 years of storming: a historical review of Tuckman's model of small group development", Human Resource Development International, 13.1 2010, pp. 111-120.

[39] Miller, D, "The stages of group development: A retrospective study of team processes", Canadian Journal of Administrative Sciences, 20.2 2003, pp. 121-134.

[40] Ellis, J, "Games for virtual team building", Proceedings of the $7^{\text {th }}$ ACM conference on Designing interactive systems, ACM 2008, pp. 295-304. 